\title{
Morfoanatomia foliar da reófita Raulinoa echinata R.S. Cowan - Rutaceae $^{1}$
}

\author{
Tagiane Arioli², Caroline Heinig Voltolini² e Marisa Santos ${ }^{2,3}$
}

Recebido em 22/03/2007. Aceito em 24/09/2007

\begin{abstract}
RESUMO - (Morfoanatomia foliar da reófita Raulinoa echinata R. S. Cowan - Rutaceae). Reófitas são espécies vegetais confinadas aos leitos de rios e riachos de fortes corredeiras, crescendo acima do nível das inundações, mas não além do alcance da ocorrência regular das rápidas enchentes. A morfoanatomia foliar de Raulinoa echinata R.S.Cowan (Rutaceae) foi investigada objetivando compreender a adaptação às peculiaridades do hábitat reofítico. As folhas de $R$. echinata são dorsiventrais e hipoestomáticas. A epiderme é uniestratificada e os estômatos são anomocíticos. As células-guarda estão dispostas acima do nível das demais células epidérmicas (característica hidromórfica), mas com átrio externo conspícuo (característica xeromórfica). Aspectos mais marcantes relacionados ao hábitat reofítico são estenofilia e presença de suberina nas paredes periclinais internas das células epidérmicas. A área foliar varia com a intensidade de exposição ao sol, a densidade estomática varia com o fluxo do rio; as espessuras dos tecidos do mesofilo variam com ambas condições. Ductos secretores e idioblastos com cristais de fosfato de cálcio ocorrem no mesofilo. Os dados revelaram plasticidade da estrutura foliar às condições peculiares do ambiente reofítico e as condições sombreadas ou expostas ao sol.
\end{abstract}

Palavras-chave: reófitas, Raulinoa echinata, características adaptativas, anatomia, folha

ABSTRACT - (Leaf morphoanatomy of the rheophyte Raulinoa echinata R. S. Cowan - Rutaceae). Rheophytes are plants confined to the beds of swift-running streams and rivers, growing above flood level but not beyond the normal reach of flash floods. Leaf morphoanatomy of the rheophyte Raulinoa echinata R.S.Cowan (Rutaceae) was investigated with a focus on understanding adaptation to the peculiarities of the rheophytic habitat. R. echinata leaves are dorsiventral and hypostomatic. The epidermis has a single layer of cells and the stomata are anomocytic. The guard cells rise above the level of the other epidermal cells (a hydromorphic characteristic), but with a conspicuous outer cavity (a xeromorphic characteristic). Prominent traits related to the rheophytic habitat are stenophylls and the presence of suberin on the inner periclinal walls of the epidermal cells. Leaf area varies with sun exposure while stomatal density varies with river flow. In $R$. echinata, mesophyll tissue thickness varies with light intensity and river flow. Secretory cavities and idioblasts with calcium phosphate crystals occur in the mesophyll. The data revealed leaf-structure plasticity in relation to the singular conditions of the rheophytic environment as well as to shade or sunlight.

Key words: rheophytes, Raulinoa echinata, adaptative characteristics, anatomy, leaf

\section{Introdução}

As reófitas constituem um grupo particular de vegetação ribeirinha. Diversas famílias têm espécies reófitas (Van Steenis 1981; 1987) e, para a região Sul do Brasil, Klein (1979) relaciona 21 famílias, das quais Euphorbiaceae, Leguminosae e Myrtaceae são as mais representativas. O termo reófita foi empregado, pela primeira vez, em 1932, por Van Steenis, do RijksHerbarium (Holanda), para designar espécies de plantas que são restritas ou exclusivas de corredeiras e cascatas, nos leitos de rios e riachos (Klein 1979). Estas plantas crescem acima do nível da água, sem distanciar-se muito das margens, e caracterizam-se por resistir às enxurradas originadas por chuvas fortes na área da cabeceira do rio
(Van Steenis 1981). Klein (1979) salienta que as reófitas devem enfrentar não só as fortes correntezas, provocadas pelas enchentes periódicas, quando estão totais ou parcialmente submersas, mas também os intensos raios solares incidentes sobre as rochas, quando as águas estão rasas.

As características adaptativas das reófitas não são tão evidentes como em outros grupos biológicos (hidrófitas, halófitas, xerófitas, entre outros), nos quais o agenciador principal do ambiente é relativamente bem definido (seca, insolação, salinidade do solo, etc.). Algumas características morfológicas das reófitas, relacionadas ao ambiente, têm sido destacadas por Klein (1979) e Van Steenis (1981; 1987): sistema radicular forte e bem desenvolvido, apto para desempenhar

\footnotetext{
1 Parte da Dissertação de Mestrado da primeira Autora, Programa de Pós-Graduação em Biologia Vegetal da Universidade Federal de Santa Catarina

2 Universidade Federal de Santa Catarina, Departamento de Botânica, 88040-900 Florianópolis, SC, Brasil

3 Autor para correspondência: marint@mbox1.ufsc.br
} 
aderência às rochas, protegendo do movimento dos cascalhos e seixos rolados; caules rijos e resistentes, porém flexíveis, suportando às tensões das correntes de água; folhas ou folíolos, em geral, estreitos ou lanceolados, evidenciando estenofilia (estreitos e longos); provavelmente floração e frutificação rápidas. Com relação à estrutura anatômica, poucos estudos têm dedicado maior aprofundamento com representantes deste grupo biológico, estando praticamente limitados a investigações com espécies ocorrentes no Japão, tais como Kato \& Imaichi (1992a; b), Imaichi \& Kato (1992; 1993), Usukura et al. (1994) e Tsukaya (2002).

Raulinoa echinata R.S. Cowan, popularmente conhecida como cutia-de-espinho, é uma reófita endêmica do Rio Itajaí-Açu (Estado de Santa Catarina, Brasil). Essa espécie recebeu atenção em estudos com abordagem química e bioatividade (Biavatti et al. 2001). Os indivíduos encontram-se nas margens encachoeiradas do rio, portanto sujeitos às adversidades proporcionadas pelas constantes cheias e vazantes.

Na relação planta-ambiente, geralmente as variações morfoanatômicas mais expressivas são observadas nas folhas (Fahn 1978; Dickison 2000). O presente trabalho teve por objetivo caracterizar os aspectos morfoanatômicos das folhas de $R$. echinata, em períodos de cheia e de vazante do rio, bem como suas variações em decorrência do fluxo do rio e da maior ou menor exposição ao sol.

\section{Material e métodos}

Raulinoa echinata é um arbusto glabro, de 2-3 m de altura, cujos troncos são finos e flexuosos, com espinhos (em alguns ausentes), suas folhas são firmecartáceas (Cowan \& Smith 1973). A idendificação foi feita por especialista e a excicata foi incorporada no acervo do Herbário Flor da Universidade Federal de Santa Catarina (Florianópolis, SC), com o registro Flor 36366.

Folhas totalmente expandidas, de quarto nó, de R. echinata, de sol e de sombra (de três indivíduos de cada tratamento), foram coletadas no Rio Itajaí-Açu, em diferentes períodos do fluxo do rio (cheias e vazantes). Algumas plantas, embora sempre marginais, estão localizadas: ou avançando um pouco no leito pedregoso do rio, onde se encontram mais expostas à irradiação solar, das quais foram retiradas as folhas de sol, excluídas as folhas mais internas parcialmente sombreadas pelas externas; ou avançando para junto da vegetação ribeirinha, sendo sombreados pelo dossel de outras espécies, das quais foram obtidas as folhas de sombra. Qualquer que seja sua localização, as plantas estão sujeitas à parcial submersão quando ocorrem as enchentes.
O clima da Bacia do Itajaí (Rio Itajaí-Açu é um dos três principais tributários) é do tipo Cfa - subtropical úmido, conforme classificação de Köeppen, sendo influenciado pela existência de altas Serras a Oeste e Sul que, no inverno, protegem dos ventos frios vindos do Sudoeste e, no verão, atuam no sentido de elevar a temperatura. A temperatura média anual é de $20,1^{\circ} \mathrm{C}$, a precipitação total anual média é de $1.596,2 \mathrm{~mm}$ e com distribuição quase uniforme das chuvas por todos os meses, com precipitação média anual de 152,4 dias (Comitê do Itajaí 2004).

Para determinar a área foliar foi feito o contorno da lâmina em papel com massa constante e os moldes foram medidos em balança digital e a massa foi relacionada com a massa de área conhecida $\mathrm{em}^{\mathrm{cm}}{ }^{2}$ do mesmo papel. O comprimento e largura das folhas foi obtido utilizando régua milimetrada. O índice foliar (IF) foi calculado pela equação: $\mathrm{IF}=\mathrm{C} / \mathrm{L}$, onde $\mathrm{C}$ é o comprimento e $\mathrm{L}$ é a largura da lâmina (Van Steenis 1987).

Terços médios da lâmina foliar e do pecíolo foram seccionados paradérmica, transversal e longitudinalmente. Amostras in vivo, seccionadas paradermicamente com lâmina de barbear e montadas entre lâmina e lamínula com gelatina-glicerinada (Kaiser 1880 - apud Kraus \& Arduin 1997), foram usadas para determinação da densidade estomática e dimensões das células-guarda e dos poros estomáticos. A contagem do número de estômatos por área, em zonas costais da lâmina foliar, foi obtida projetando as imagens, com câmara clara acoplada a microscópio óptico, sobre área delimitada conhecida. Imagens das células-guarda e poro projetadas foram medidas para determinar as dimensões.

Testes histoquímicos, em material in vivo foram utilizados: reativo de Steimetz, para identificação de suberina, lignina, cutina, celulose, mucilagem, amido (Costa 1982); Sudan IV, para detecção de óleos, cutina e suberina (Costa 1982); floroglucinol/ $\mathrm{HCl}$, para detecção de lignina (Costa 1982); tionina, para detecção de mucilagem (Purvis et al. 1964 - apud Kraus \& Arduin 1997); ácidos clorídrico, sulfúrico e acético, para detecção da natureza química dos cristais (Evans 1989).

Amostras fixadas em glutaraldeído 2,5\%, tamponadas com fosfato de sódio $0,1 \mathrm{M}, \mathrm{pH} 7,2$, foram desidratadas em série etílica gradual (Ruzin 1999), infiltradas em parafina e coradas com safranina e verde firme (Johansen 1940) ou azul de astra/fucsina básica (Luque et al. 1996). Estas preparações serviram para análise estrutural e determinação da espessura da lâmina foliar e tecidos constituintes, em MO (Microscópio Óptico). Fotomicrografias foram obtidas em fotomicroscópio Leica MPS 30 DMLS e posteriormente digitalizadas. Diagramas foram realizados em microscópio óptico Zeiss-Jena-Loboval 4, com auxílio 
de câmara clara. Para determinar dimensões foi utilizada ocular micrometrada.

Para análise ultraestrutural amostras fixadas e desidratadas foram imersas em HMDS (hexametildesilasane), como meio substitutivo de ponto crítico de $\mathrm{CO}_{2}$ que, pelo processo de sublimação, reduz a tensão superficial, evitando o colapso das estruturas (Bozzola $\&$ Russel 1991). As amostras secas foram aderidas sobre suportes de alumínio, com auxílio de fita de carbono dupla face, e cobertas com $20 \mathrm{~nm}$ de ouro, foram observadas e documentadas em MEV (Microscópio Eletrônico de Varredura), marca Phillips, modelo XL30. Para identificação dos elementos químicos constituintes dos cristais foi utilizado detector de raios-X de $\mathrm{Si}-\mathrm{Li}$ com janela da microssonda Super Ultra Thin Window, com sistema Link-Oxford EDX, acoplado ao MEV.

As amostras foram retiradas de três folhas (exceto para área e índice folhas, quando foram usadas 30 folhas), de cada um dos três indivíduos dos dois tratamentos. $\mathrm{O}$ número mínimo amostral foi calculado pela equação $\mathrm{n}=\left(\mathrm{t}^{2} \cdot \mathrm{s}^{2}\right) \cdot \mathrm{d}^{-2}$, onde " $\mathrm{t}$ " é dado pela tabela de Student (considerando n-1, para significância de 0,05 ), "s" é o desvio padrão e "d" é igual a E/100.média, onde $E=10$ para $10 \%$ de probabilidade, valor considerado satisfatório (Sokal \& Rohlf 1969). Os dados dos quatro tratamentos (sol, sombra, vazante, cheia) foram comparadas por análise de variância (análise multifatorial) e teste Tukey (ao nível de significância de 5\%), através do programa computacional Statgraphics (1993).

\section{Resultados e discussão}

A lâmina foliar de R. echinata (Fig. 1) é simples e simétrica, com forma obovada do tipo oblanceolada, com ápice, geralmente retuso, e, por vezes, emarginado, e a base cuneada. A área foliar varia com o tratamento considerado (Tab. 1): folhas de sol são menores que as de sombra, tanto entre aquelas coletadas no período de vazante do rio, quanto no período de cheias.

Lee et al. (1996) ressaltam que, em locais sombreados, a expansão da área foliar aumenta a superfície receptora de luz. Conforme Taiz \& Zeiger (2004), uma menor área foliar determina uma redução na taxa de transpiração, conservando, efetivamente, um suprimento de água limitado por um período mais longo. Portanto, em $R$. echinata evidencia-se a plasticidade da folha em resposta à intensidade luminosa, encontrando-se folhas mais amplas quando sombreadas pela vegetação ribeirinha.

Folhas de sombra coletadas em períodos de vazante e comparadas com aquelas de cheias mostraram diferenças na área foliar, não ocorrendo o mesmo com as folhas de sol (Tab. 1). Provavelmente, as folhas de sombra da vazante expandiram mais a lâmina foliar em virtude de não estarem submersas e/ou sujeitas à turbulência do rio. Por outro lado, o período de cheias contribui para uma renovação dos nutrientes do substrato, favorecendo o desenvolvimento foliar do período subseqüente (vazante).

Estas variações de área foliar resultam da variação no comprimento da lâmina. Comparando-se folhas de sol e sombra de um mesmo período de fluxo do rio, ou folhas de vazante com as de cheias, com mesma condição de exposição à luz, não se verificam variações na largura (Tab. 1). Este fato é de grande importância para assegurar a estenofilia nas folhas de $R$. echinata. De acordo com Imaichi \& Kato (1992), estenofilia é uma adaptação morfológica que reduz a probabilidade de rompimento das lâminas foliares em espécies de hábitats reofíticos, onde há inundações de águas com turbulências fortes e rápidas. Estes autores, estudando espécies reófitas e não-reófitas, observaram que quando as plantas estão submersas durante as cheias, as folhas das reófitas permanecem intactas, enquanto as de nãoreófitas são destruídas por injúrias mecânicas.

Com relação às características anatômicas, as lâminas foliares de $R$. echinata são dorsiventrais e hipoestomáticas. Folhas dorsiventrais são comuns em Rutaceae (Metcalfe \& Chalk 1957). Os aspectos histológicos qualitativos das folhas dos quatro tratamentos são similares, distinguindo-se quantitativamente.

A epiderme é uniestratificada, com paredes anticlinais retas a sub-retas (Fig. 2). Metcalfe \& Chalk (1979) referem que os estômatos de Rutaceae são do tipo paracítico, porém em $R$. echinata são do tipo anomocítico (Fig. 3). As células-guarda (Fig. 4, 5) posicionam-se acima do nível das demais células epidérmicas, característica considerada na literatura como hidromorfa (Napp-Zinn 1984; Dickison 2000). Entretanto, ocorre um átrio externo conspícuo (Fig. 4), característica considerada xeromorfa, por favorecer a redução da transpiração (Eames \& MacDaniels 1947; Fahn \& Cutler 1992). Tais aspectos evidenciados na estrutura estomática de $R$. echinata podem ser importantes como estratégia para suportar os contrastes de submersão, nas cheias, e exposição à intensa irradiação solar, durante as vazantes do rio.

A densidade estomática é menor nas folhas de sombra em períodos de cheia, em relação aos demais tratamentos (Tab. 1). O número de estômatos por área pode variar, dependendo das condições ambientais (umidade, temperatura, luz) às quais a folha está sujeita durante a divisão e alongamento das células (Parkhurst 1978; Muchow \& Sinclair 1989; Paoletti \& Gellini 1993). Diversos estudos têm demonstrado que com maior 
intensidade luminosa ocorre aumento na densidade estomática (Allard et al. 1991; Abrans et al. 1992; Ashton \& Berlyn 1994; Duz et al. 2004; Fermino Jr. et al. 2004), o que determina uma menor distância entre os estômatos conduzindo a redução da transpiração (Larcher 2000). Em R. echinata as condições ambientais afetam a densidade estomática, mas a interação entre os fatores abióticos parece ser mais complexa do que apenas o efeito da luz e regime de fluxo do rio, estando ainda associada a alterações nas dimensões das células-guarda.
Quando há aumento da intensidade luminosa no ambiente, a perda de água pode ser minimizada pela redução do tamanho das células-guarda (Abrans et al. 1992; Duz et al. 2004).

$\mathrm{O}$ fato de que entre folhas de sol e de sombra de $R$. echinata, no período de vazante, não ter mostrado diferenças na densidade estomática, pode ser decorrente da incidência indireta resultante da reflexão dos raios solares pela superfície da água, mais límpida e calma. Entretanto, foram afetadas as dimensões das células-

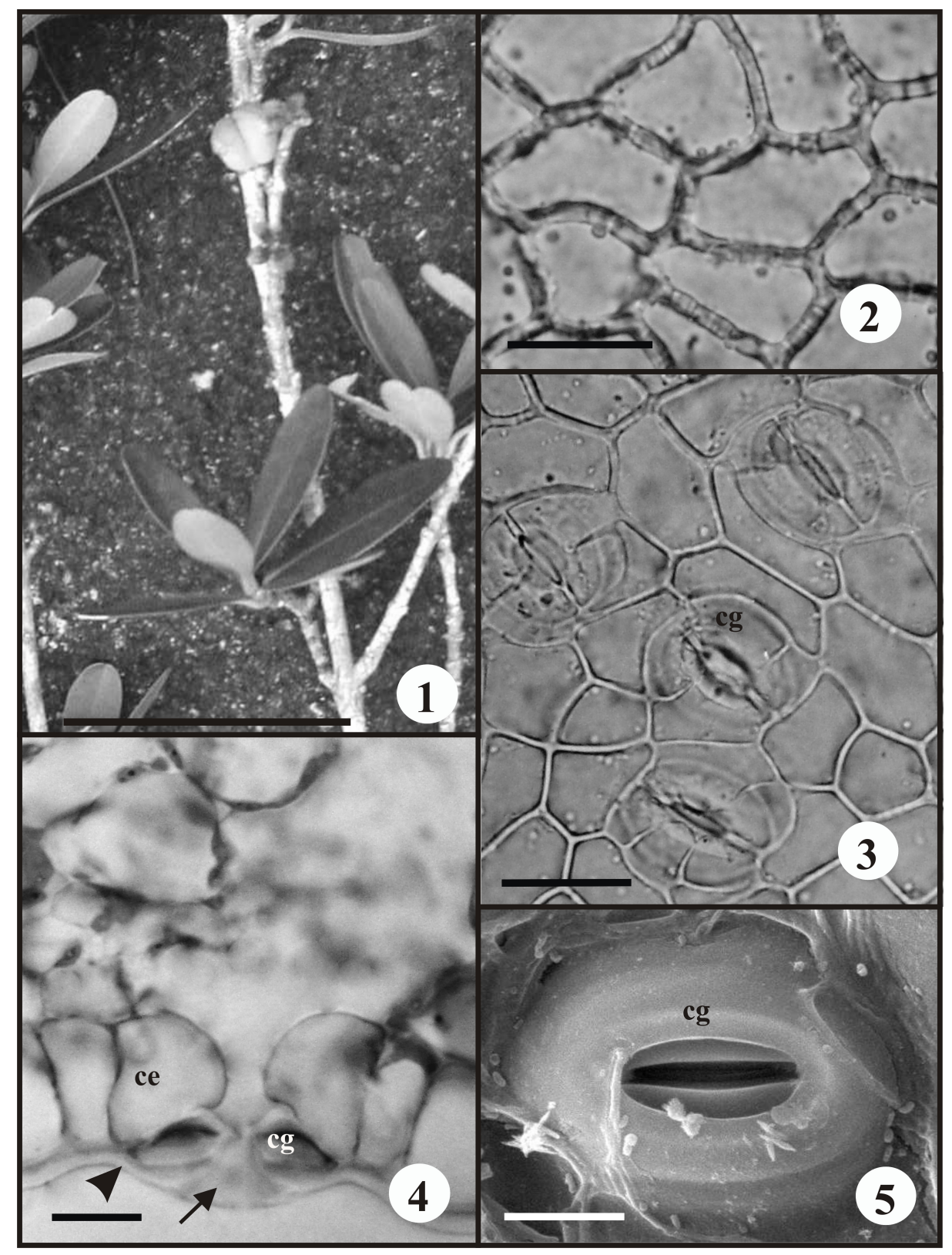

Figuras 1-5. Raulinoa echinata R.S.Cowan. 1. Ramo com folhas estreitas e alongadas (seta) (Barra = $5 \mathrm{~cm}$ ). 2-3. Vistas frontais da epiderme foliar, em MO (Barras $=30 \mu \mathrm{m})$. 2. Face adaxial, evidenciando as paredes anticlinais. 3. Face abaxial. 4. Secção transversal de folha na região estomática, em MO $($ Barra $=10 \mu \mathrm{m})$. Note as células-guarda localizadas acima do nível das células vizinhas e átrio externo conspícuo (seta) e membrana cuticular delgada (cabeça de seta). 5. Estômato em vista frontal, em MEV (Barra $=10 \mu \mathrm{m})$. ce - célula epidérmica; cg - célula-guarda. 
Tabela 1. Área, índice e dimensões das lâminas, densidade estomática, dimensões das células-guarda e do poro estomático, espessura total e das estruturas constituintes da lâmina de folhas de sol e de sombra de Raulinoa echinata R.S. Cowan, nos períodos de vazante e cheia do Rio Itajaí-Açu, SC, Brasil.

\begin{tabular}{|c|c|c|c|c|}
\hline & \multicolumn{2}{|c|}{ Período de vazante } & \multicolumn{2}{|c|}{ Período de cheia } \\
\hline & sol & sombra & sol & sombra \\
\hline Área foliar $\left(\mathrm{cm}^{2}\right)$ & $5,12 \pm 1,75^{\mathrm{ab}}$ & $6,98 \pm 1,85^{\mathrm{c}}$ & $4,56 \pm 1,04^{\mathrm{a}}$ & $5,60 \pm 1,24^{\mathrm{b}}$ \\
\hline Índice foliar & $2,75 \pm 0,30^{\mathrm{a}}$ & $3,47 \pm 0,61^{b}$ & $3,17 \pm 0,44^{\mathrm{b}}$ & $3,33 \pm 0,51^{\mathrm{b}}$ \\
\hline Comprimento da lâmina foliar $(\mathrm{cm})$ & $4,35 \pm 0,66^{\mathrm{a}}$ & $5,71 \pm 0,94^{\mathrm{c}}$ & $4,67 \pm 0,62^{\mathrm{a}}$ & $5,16 \pm 0,55^{\mathrm{b}}$ \\
\hline Largura da lâmina foliar (cm) & $1,59 \pm 0,23^{\mathrm{ab}}$ & $1,66 \pm 0,24^{\mathrm{b}}$ & $1,48 \pm 0,17^{\mathrm{a}}$ & $1,57 \pm 0,18^{\mathrm{ab}}$ \\
\hline Densidade estomática ( $\mathrm{n}^{\circ}$ de estômatos $/ \mathrm{mm}^{2}$ ) & $240,00 \pm 38,00^{\mathrm{b}}$ & $262,20 \pm 55,65^{b}$ & $256,30 \pm 38,15^{\mathrm{b}}$ & $198,50 \pm 39,98^{a}$ \\
\hline Comprimento da célula-guarda $(\mu \mathrm{m})$ & $29,50 \pm 2,79^{b}$ & $27,50 \pm 2,69^{a}$ & $30,90 \pm 2,26^{\mathrm{b}}$ & $31,10 \pm 2,11^{\mathrm{b}}$ \\
\hline Largura da célula-guarda $(\mu \mathrm{m})$ & $9,90 \pm 1,59^{\mathrm{b}}$ & $8,50 \pm 1,97^{\mathrm{a}}$ & $9,60 \pm 1,53^{\mathrm{ab}}$ & $9,20 \pm 1,28^{\mathrm{ab}}$ \\
\hline Comprimento do poro estomático $(\mu \mathrm{m})$ & $14,30 \pm 2,22^{\mathrm{ab}}$ & $13,90 \pm 1,75^{\mathrm{a}}$ & $14,50 \pm 2,00^{\mathrm{ab}}$ & $15,50 \pm 1,68^{\mathrm{b}}$ \\
\hline Largura doporo estomático $(\mu \mathrm{m})$ & $8,20 \pm 1,54^{\mathrm{b}}$ & $7,00 \pm 1,59^{\mathrm{a}}$ & $9,40 \pm 2,06^{\mathrm{c}}$ & $9,40 \pm 1,53^{\mathrm{c}}$ \\
\hline Espessura total da lâmina foliar $(\mu \mathrm{m})$ & $247,00 \pm 23,97^{a}$ & $256,60 \pm 15,90^{\text {ab }}$ & $268,40 \pm 28,93^{\mathrm{b}}$ & $246,90 \pm 23,34^{\mathrm{a}}$ \\
\hline Espessura do mesofilo $(\mu \mathrm{m})$ & $212,10 \pm 23,52^{\mathrm{ab}}$ & $215,60 \pm 14,82^{\mathrm{ab}}$ & $227,00 \pm 30,81^{\mathrm{b}}$ & $207,20 \pm 21,86^{a}$ \\
\hline Espessura do parênquima paliçádico $(\mu \mathrm{m})$ & $64,50 \pm 7,38^{\mathrm{b}}$ & $57,10 \pm 7,26^{\mathrm{a}}$ & $77,80 \pm 15,62^{\mathrm{c}}$ & $64,60 \pm 9,11^{\mathrm{b}}$ \\
\hline Espessura do parênquima esponjoso $(\mu \mathrm{m})$ & $147,60 \pm 21,08^{\mathrm{ab}}$ & $158,50 \pm 16,95^{\mathrm{b}}$ & $149,20 \pm 23,40^{\mathrm{ab}}$ & $142,60 \pm 19,09^{\mathrm{a}}$ \\
\hline Espessura da epiderme na face adaxial $(\mu \mathrm{m})$ & $20,60 \pm 2,63^{a}$ & $22,90 \pm 2,95^{\mathrm{b}}$ & $22,90 \pm 3,81^{\mathrm{b}}$ & $21,1 \mathrm{~s} 0 \pm 3,60^{\mathrm{ab}}$ \\
\hline Espessura da epiderme na face abaxial $(\mu \mathrm{m})$ & $14,30 \pm 2,31^{\mathrm{a}}$ & $18,10 \pm 2,30^{\mathrm{b}}$ & $18,50 \pm 2,32^{b}$ & $18,64 \pm 2,68^{\mathrm{b}}$ \\
\hline
\end{tabular}

Nota: $\mathrm{n}=30$, para cada parâmetro, de cada tratamento. Letras diferentes, comparadas na horizontal, indicam diferenças estatisticamente significativas entre as médias, ao nível de $5 \%$ de probabilidade pelo teste de Tukey.

guarda (Tab. 1). Nas cheias, as águas turbulentas e barrentas, reduzem ou mesmo não propiciam tal reflexão, hipótese que pode ser reforçada com a constatação da distinção na densidade estomática e no comprimento das células-guarda entre folhas de sombra de vazante e de cheias.

Os resultados obtidos para o comprimento do poro estomático indicam a influência do regime de fluxo do rio apenas em folhas de sombra, enquanto a largura é afetada tanto entre folhas de sol, quanto entre folhas de sombra (Tab. 1). Conforme Larcher (2000), o grau de abertura estomática altera-se durante a ontogênese, ajustando-se continuamente às oscilações dos fatores ambientais. Esse mesmo autor ressalta que a causa para uma redução no grau de abertura estomática pode estar associada a uma redução da intensidade luminosa, ao ar seco, ao déficit hídrico e/ou às temperaturas extremas. Os resultados verificados em $R$. echinata indicam que, durante a ontogênese da estrutura estomática, há influências das condições de vazante-cheias, entretanto, estas estão associadas a outros fatores, tais como reflexão solar e outros, não avaliados no presente estudo, como teor de nutrientes do substrato, temperatura e umidade do ar.

Outra característica de fundamental importância na relação planta-ambiente, assegurando o equilíbrio hídrico interno, é a qualidade de impermeabilização e reflexão solar exercida pelo tecido de revestimento. A membrana cuticular, que recobre a superfície externa das partes aéreas, contribui para o controle hídrico, desempenhando importante função na reflexão dos raios solares (Eames \& MacDaniels 1947; Holloway 1980; Gutschick 1999; Dickison 2000). Cutícula espessa e densos depósitos de ceras epicuticulares foram características encontradas em pteridófitas reófitas, por Imaichi \& Kato (1992) e Kato \& Imaichi (1992b). Conforme estes autores, isto constitui importante adaptação ao hábitat reofítico, o qual alterna dias de ampla exposição ao sol com dias de submergência, evitando excessiva transpiração ou repelindo a entrada de água, respectivamente. Porém, a epiderme em $R$. echinata é delimitada externamente por uma delgada membrana cuticular (Fig. 4). Além disso, a análise ultraestrutural revelou raros depósitos de ceras epicuticulares e, quando presentes, apresentavam-se bastante esparsos. Portanto, conforme dados da literatura, esta reófita parece mostrar-se pouco protegida, tanto para evitar desidratação em períodos de maior exposição (vazante), quanto para evitar absorção excessiva de água quando a planta pode ficar parcialmente submersa em períodos de cheia. Entretanto, nas paredes periclinais internas e anticlinais das células epidérmicas de $R$. echinata há deposição de suberina, a qual deve ter um papel relevante na impermeabilização, isolando os tecidos mais internos durante as cheias do rio. Diversos trabalhos têm registrado a presença de suberina em paredes celulares desempenhando importante barreira ao fluxo apoplástico, como conseqüência de suas propriedades impermeabilizantes (Hattersley \& Browning 1981; Ryser 1992).

O mesofilo das folhas de $R$. echinata está 
constituído por parênquimas paliçádico e esponjoso (Fig. 6-9). O parênquima paliçádico, uniestratificado e localizado adaxialmente, é constituído por células estreitas, alongadas e justapostas. Próximo à nervura mediana, por vezes, torna-se biestratificado. O parênquima esponjoso, localizado abaxialmente, é formado por células com forma e tamanho irregulares, contendo grande quantidade de grãos de amido, e mostra amplos espaços intercelulares.
O parênquima paliçádico é mais espesso em folhas de sol do que em folhas de sombra, tanto no período de vazante quanto no período de cheia do rio, sendo mantida a espessura do parênquima esponjoso (Tab. 1). Isto resulta do alongamento das células paliçádicas, não ocorrendo aumento no número de estratos celulares (Fig. 6-9). Além disto, o parênquima paliçádico é o responsável pela maior espessura de lâminas foliares mais expostas ao sol, em relação às de sombra, formadas no período

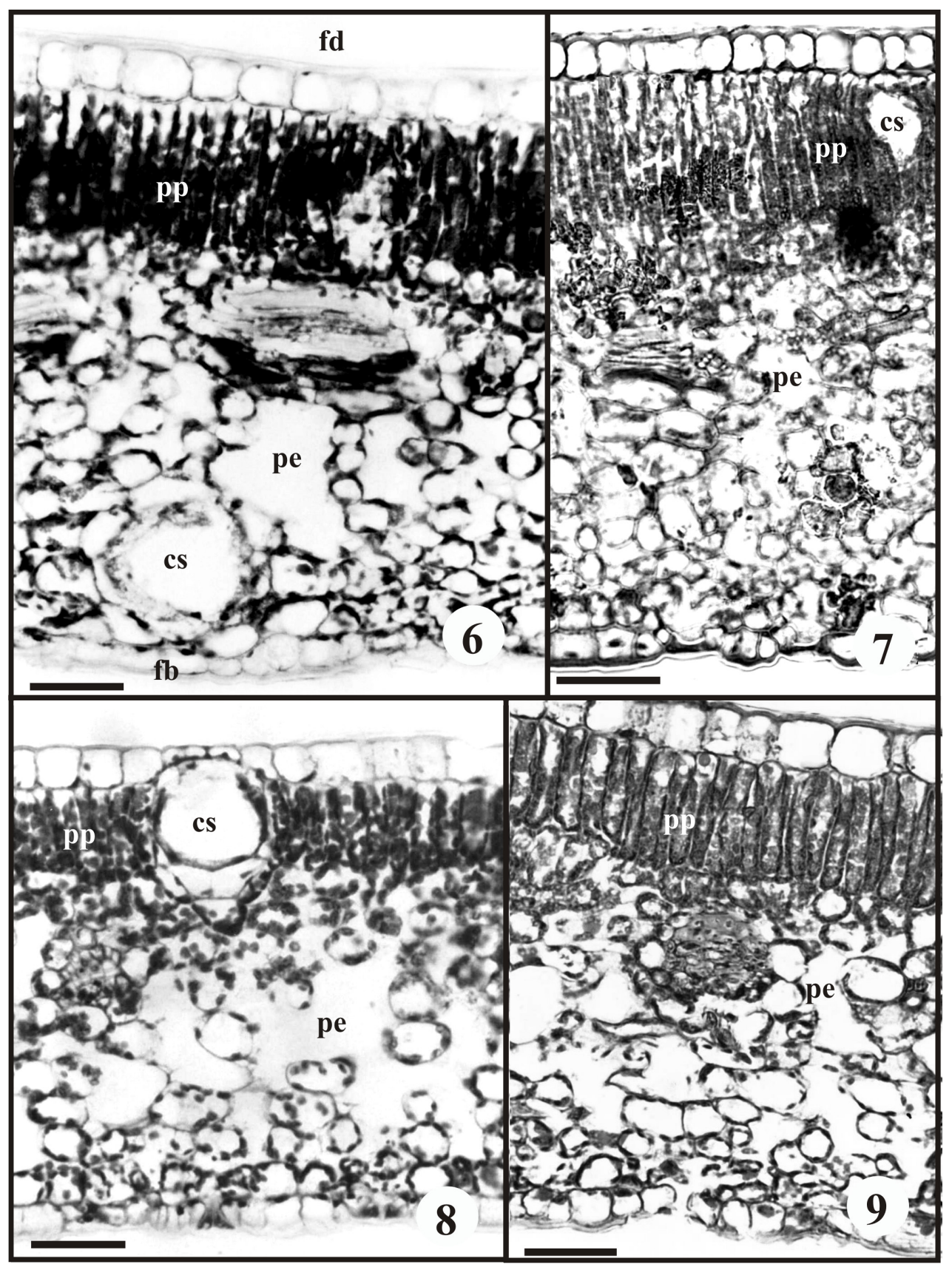

Figuras 6-9. Secções transversais de lâmina foliar de Raulinoa echinata R.S. Cowan, em MO (Barras $=50$ 4 m). 6 e 8 . Período de vazante. 7 e 9. Período de cheias. 6-7. Folhas de sol. 8-9. Folhas de sombra. cs - cavidade secretora; fb - face abaxial; fd - face adaxial; pp - parênquima paliçádico; pe - parênquima esponjoso 
de cheia (Tab. 1). A maior exposição à luz eleva a espessura da lâmina foliar e do tecido paliçádico (Eames \& MacDaniels 1947; Napp-Zinn 1984; Syvertsen et al. 1995; Lambers et al. 1998; Taiz \& Zeiger 2004). Em $R$. echinata constata-se que a maior intensidade luminosa atua estimulando a plasticidade, alongando as células do parênquima paliçádico. Porém, este mesmo fator abiótico também mostra relação na redução da espessura das células epidérmicas no período de vazante.

O fluxo do rio também influencia a espessura do parênquima paliçádico, entretanto somente as folhas de sombra tiveram o parênquima esponjoso afetado, mostrando menor espessura no período de cheia (Tab. 1). Portanto, o maior espessamento do parênquima paliçádico, associado ao aumento da espessura da epiderme e manutenção da espessura do parênquima esponjoso, conduziram a um aumento da espessura da lâmina nas folhas coletadas em período de cheia, relativamente àquelas do período de vazante. Porém, apesar da influência do fluxo do rio sobre a espessura dos tecidos parenquimáticos, em folhas de sombra, isto não é evidenciado nos dados referentes à espessura total da lâmina foliar, exatamente porque nas cheias há aumento na espessura do paliçádico e redução do esponjoso (Tab. 1).

No bordo foliar de R. echinata (Fig. 10), as características histológicas mantêm-se similares ao restante da lâmina, exceto pela presença de um estrato de células colenquimáticas aclorofiladas.

A nervura mediana, em secção transversal (Fig. 11), mostra-se convexa na face abaxial e quase plana na face adaxial. Sob a epiderme ocorre colênquima angular, mais desenvolvido adaxialmente. O clorênquima, na face adaxial, é contínuo com o mesofilo, podendo apresentar-se em paliçada nas folhas mais expostas ao sol. O sistema vascular está constituído por dois feixes vasculares colaterais, um maior, em forma de arco, com o floema voltado para face abaxial, e outro menor em disposição inversa ao primeiro, isto é, com floema voltado para face adaxial (Fig. 12). Quando estes feixes estão mais desenvolvidos, podem estar tão próximos (Fig. 11) que se assemelham ao tipo anficrival. Cordões de fibras delimitam externamente o floema (Fig. 12). Entre o xilema e floema observa-se freqüentemente a presença de células com características cambiais. Folhas persistentes de grande parte das gimnospermas e de muitas angiospermas, conforme Eames \& MacDaniels (1947), possuem crescimento secundário. Kasapligil (1951), Santos \& Oliveira $(1988 ; 1995)$ registram a ocorrência de câmbio vascular em folhas de Lauraceae. Entretanto, Esau (1959) salienta que tanto as células procambiais, quanto as cambiais, apresentam seriação radial e as células procambiais tardias podem ter dimensões radiais pequenas, como é típico de células cambiais. Portanto, em $R$. echinata, estas células podem consistir em atividade tardia do procâmbio ou realmente constituirem um câmbio vascular. Em qualquer dos casos indica uma persistência mais prolongada das folhas.

O pecíolo, em $R$. echinata, apresenta-se com a face adaxial plana (Fig. 13) e com tricomas unicelulares pontiagudos. Sob a epiderme ocorre colênquima anelar, seguido de parênquima aclorofilado. O sistema vascular mostra-se similar ao descrito para nervura mediana.

Duas estruturas presentes nas folhas (entre células do mesofilo, da nervura mediana e do córtex do pecíolo) de R. echinata merecem destaque: cavidades secretoras e idioblastos com cristais. As cavidades (Fig. 14) são delimitadas por células secretoras e contém óleos. A presença de cavidades secretoras é referida na literatura como manchas translúcidas em folhas de espécies de Rutaceae (Solereder 1908; Metcalfe \& Chalk 1957). Vistas frontais da superfície epidérmica de $R$. echinata, possibilitam evidenciar a presença sub-adjacente das cavidades secretoras, ocorrendo ausência de estômatos e distinta conformação das células epidérmicas (Fig. 15), a transparência é favorecida pela redução da altura destas células epidérmicas.

Cristais (Fig. 16) encontram-se fartamente distribuídos em idioblastos no mesofilo, na nervura mediana e no pecíolo. Solereder (1908) e Metcalfe \& Chalk (1957) mencionam a presença de cristais agrupados no mesofilo de numerosas espécies de Rutaceae. Microanálises químicas revelaram que estes cristais, em $R$. echinata, contêm grande quantidade de fósforo e cálcio (Fig. 17), sendo que o primeiro sempre apresenta percentagens relativas similares ao segundo. Usualmente, as plantas apresentam cristais cuja natureza química é oxalato de cálcio, porém outros sais de cálcio podem ser encontrados (Metcalfe \& Chalk 1983). Raramente a literatura menciona a presença de fosfato de cálcio na forma cristalina, como feito por Arnott \& Pautard (1970, apud Macnish et al. 2003). Conforme Taiz \& Zeiger (2004) íons fosfatos são absorvidos pelas raízes e incorporados em uma variedade de compostos orgânicos, incluindo açúcares, fosfatos, fosfolipídios e nucleotídeos. Segundo estes autores, o fósforo está diretamente relacionado ao armazenamento de energia e integridade estrutural, principalmente das membranas vegetais. Assim, o fósforo é um elemento essencial ao crescimento e desenvolvimento das plantas sendo exigido em quantidades relativamente pequenas, porém à medida que vai sendo aproveitado pela planta necessita ser reposto (Mello et al. 1989). Os cristais de R. echinata podem estar associados à manutenção dos processos fisiológicos vitais, durante os períodos de cheia, bem como com a disponibilização de reserva extra para períodos pós-cheia, quando as atividades metabólicas devem ser mais 


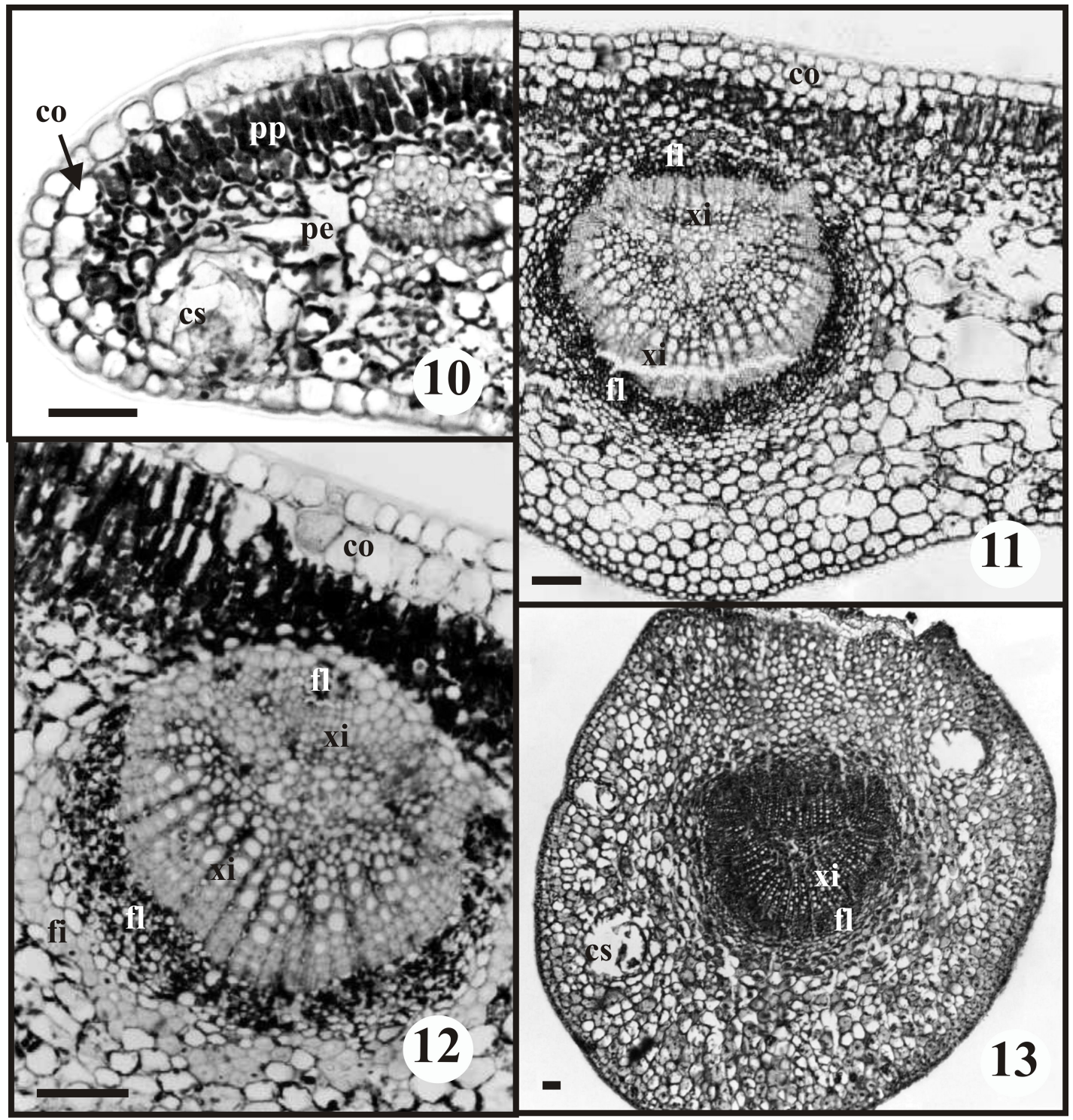

Figuras 10-13. Seções transversais de folhas de Raulinoa echinata R.S. Cowan, em MO (Barras $=50 \mu \mathrm{m})$. 10. Bordo evidenciando estrato único de colênquima. 11-12. Nervura mediana. Note feixe vascular menor, adaxialmente, com xilema e floema em posição inversa ao feixe vascular maior. 13. Pecíolo, com sistema vascular similar ao da nervura mediana. co - colênquima; cs - cavidade secretora; fi - fibras; fl - floema; pe - parênquima esponjoso; pp - parênquima paliçádico; $\mathrm{x}$ - xilema

intensas, de modo a assegurar os processos reprodutivos em períodos favoráveis. Por outro lado, as substâncias constituintes destes cristais, presentes em grande quantidade na planta, podem ter interesse medicinal. Extratos de $R$. echinata têm apresentado bons resultados na inibição de formas do Trypanossoma cruzi, visando o tratamento da Doença de Chagas (Biavatti et al. 2001). Os princípios ativos podem não ter relação com as estruturas aqui registradas, porém a detecção destas aponta para necessidade de investigações em outras áreas de estudos.

O conhecimento das características morfoanatômicas das folhas de $R$. echinata possibilitou interpre- tações acerca da adaptação desta reófita às peculiaridades do ambiente onde ocorre. Nenhuma característica exclusiva de reófitas pode ser reconhecida. Tratam-se de características hidromorfas e xeromorfas, que reunidas possibilitam a sobrevivência em condições adversas extremas, de submersão com turbulência ou de elevada exposição à irradiação solar no ambiente reofítico.

\section{Agradecimentos}

Os autores agradecem ao Funpesquisa-UFSC, pelo auxílio financeiro para o desenvolvimento do trabalho e ao Prof. Dr. Ademir Reis pelo auxílio nas coletas de 


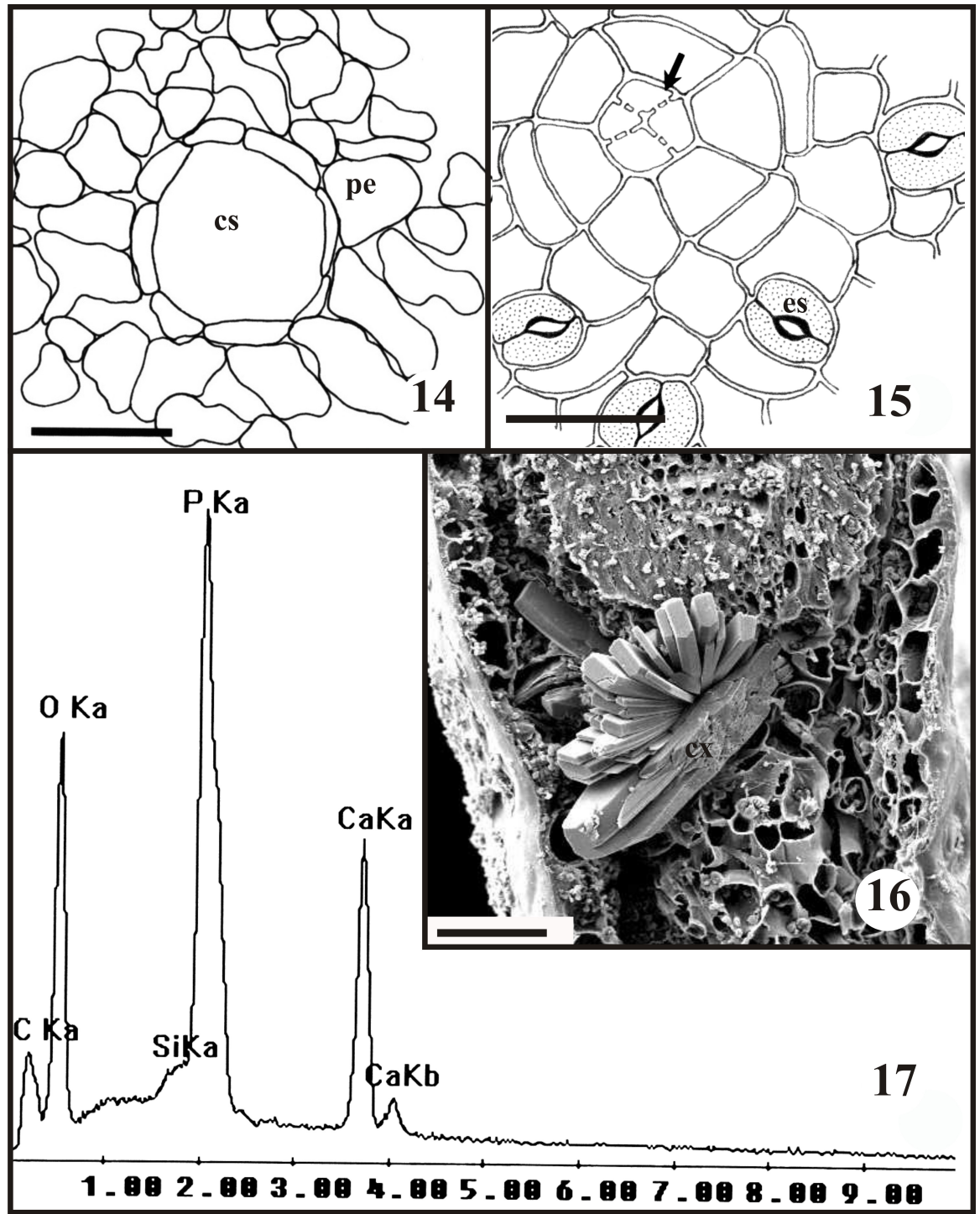

Figuras 14-17. Raulinoa echinata R.S. Cowan (Barras $=50 \mu \mathrm{m})$. 14 e 15. Diagramas de secções paradérmicas da lâmina foliar na região da cavidade secretora, em MO. 14. Plano mais interno, com cavidade delimitada por células secretoras. 15. Plano mais externo, epiderme na região da cavidade mostra-se modificada (seta). 16. Detalhe destacando os cristais no mesofilo, em MEV. 17. Espectro da microanálise química, em EDX/MEV, referente aos cristais observados na figura 16, com correspondente a quantificação proporcional dos elementos químicos detectados: Ca (32,70\%), O (30,17\%), P (29,44\%), C (5,88\%), Si (1,82\%). cg - célula-guarda; cr - cristal; cs - célula secretora; pe - parênquima esponjoso.

R. echinata. Arioli agradece à Capes pela bolsa concedida durante a realização deste trabalho.

\section{Referências bibliográficas}

Abrans, M.C.; Kloeppel, B.D. \& Kubiske, M.E. 1992. Ecophysiological and morphological responses to shade and drought in two contrasting ecotypes of Prunus setorina. Tree Physiology 10: 343-355.

Allard, G.; Nelson, C.J. \& Pallardy, S.G. 1991. Shade effects on growth of tall fescue: I. leaf anatomy and dry matter partitioning. Crop Science 31: 163-167.

Ashton, P.M.S. \& Berlyn, G.P. 1994. A Comparison of Leaf Physiology and Anatomy of Quercus (Section ErythrobalanusFagaceae) Species in Different Light Environments. American Journal of Botany 81: 589-597.
Biavatti, M.W.; Magalhaes, C.M.I.; Pagnocca, F.C.; Fernandes, J.B.; Silva, M.F.G.F.; Vieira, P.C. \& Albuquerque, S. 2001. Chemistry and bioactivity of Raulinoa echinata Cowan, an endemic Brazilian Rutaceae species. Phytomedicine 8: 121-124.

Bozzola, J.J. \& Russel, L.D. 1991. Electron Microscopy. Principles and Techniques for Biologists. Boston, Jones and Barlett.

Comitê do Itajaí. 2004. Agência de Água do Vale do Itajaí. Disponível em: <http://www.comiteitajai.org.br>. (Acesso em 13/06/2004).

Costa, A.F. 1982. FarmacognosiaB V. III. Farmacognosia Experimental. 2 ed. Lisboa, Fundação Calouste Gulbenkian.

Cowan, R.S. \& Smith, L.B. 1973. Rutáceas. Pp. 47-50. In: Reitz (ed.). Flora Ilustrada Catarinense. Herbário Barbosa Rodrigues, Itajaí.

Dickison, W.C. 2000. Integrative Plant Anatomy. USA, Academic Press. 
Duz, S.R.; Siminski, A.; Santos, M. \& Paulilo, M.T.S. 2004. Crescimento inicial de três espécies arbóreas da Floresta Atlântica em resposta à variação na quantidade de luz. Revista Brasileira de Botânica 27: 587-596.

Eames, A.J. \& MacDaniels, L.H. 1947. An Introduction to Plant Anatomy. 2 ed. USA, McGraw-Hill.

Esau, K. 1959. Anatomía Vegetal. Barcelona, Ed. Omega.

Evans, W.C. 1989. Trease and Evans' Pharmacognosy. London, Baillière Tindall.

Fahn, A. 1978. Anatomia Vegetal. Madrid, H. Blume.

Fahn, A. \& Cutler, D.F. 1992. Xerophytes. Germany, Gebrüder Borntraeger.

Fermino-Jr., P.C.P.; Paulilo, M.T.S.; Reis, A. \& Santos, M. 2004. Espécies pioneiras e climácicas da floresta ombrófila densa: anatomia foliar comparada. Insula 33: 21-37.

Gutschick, V.P. 1999. Biotic and abiotic consequences of differences in leaf structure. New Phytologist 143: 3-18.

Hattersley, P.W. \& Browning, A.J. 1981. Occurrence of the suberized lamella in leaves of Grasses of different photosynthetic types. I. In parenchymatous bundle sheaths and PCR ("Kranz") sheaths. Protoplasma 109: 371-401.

Holloway, P.J. 1980. Structure and histochemistry of plant cuticular membranes: an overview. Pp. 1-30. In: D.F. Cutler; K.L. Alvin \& C.E. Price (eds.). The Plant Cuticle. London, Academic Press.

Imaichi, R. \& Kato, M. 1992. Comparative Leaf Development of Osmunda lancea and O. japonica (Osmundaceae): heterochronic origin of rheophytic sthenophylly. The Botanical Magazine Tokyo 105: 199-213.

Imaichi, R. \& Kato, M. 1993. Comparative leaf morphology of young sporophytes of rheophytic Osmunda lancea and dryland $O$. japonica. Journal of Plant Research 106: 37-45.

Johansen, D.A. 1940. Plant Microtechnique. New York, McGraw Hill.

Kato, M. \& Imaichi, R. 1992a. Leaf anatomy of tropical fern rheophytes with its evolutionary and ecological implications. Canadian Journal of Botany 70: 165-174.

Kato, M. \& Imaichi, R. 1992b. A broad-leaved variant of the fern rheophyte, Tectaria lobbii. International Journal of Plant Science 153: 212-216.

Klein, R.M. 1979. Reófitas no Estado de Santa Catarina, Brasil. Pp.159-169. In: Anais do XXX Congresso Nacional de Botânica. Campo Grande 1979. Campo Grande, SBB.

Kasapligil, B. 1951. Morphological and ontogenetic studies of Umbellularia californica Nutt and Laurus nobilis L. University of California Publications in Botany 25: 115-240.

Kraus, J.E \& Arduin, M. 1997. Manual básico de métodos em morfologia vegetal. Seropédica, Edur.

Lambers, H.; Stuart, F. \& Pons, T.L. 1998. Plant Physiological Ecology. New York, Springers-Verlag.

Larcher, W. 2000. Ecofisiologia Vegetal. São Carlos, Rima Artes e Textos.

Lee, D.W.; Baskaran, K.; Mansor, M.; Mohamad, H. \& Yap, S.K. 1996. Irradiance and spectral quality affect Asian tropical rain forest tree seedling development. Ecology 77: 568-580.

Luque, R.; Sousa, H.C. \& Kraus, J.E. 1996. Métodos de coloração de Roeser (1972) - modificado e Kropp (1972) visando a substituição do azul de astra por azulão $8 \mathrm{GS}$ ou $8 \mathrm{GX}$. Acta Botanica Brasilica 10: 199-212.
Macnish, A.J.; Irving, D.E.; Joyce, D.C.; Vithanage, V.; Wearing, H.; Webb, R.I. \& Frost, R.L. 2003. Identification of intracellular calcium oxalate crystals in Chamelaucium uncinatum (Myrtaceae). Australian Journal of Botany 51: 565-572.

Mello, F.A.F.; Brasil Sobrinho, M.O.C.; Arzolla, R.I.; Cobra Neto, A. \& Kiehl, J.C. 1989. Fertilidade do Solo. Piracicaba, Ed. Livraria Nobel.

Metcalfe, C.R. \& Chalk, L. 1957. Anatomy of the Dicotyledons. Oxford, University Press.

Metcalfe, C.R. \& Chalk, L. 1979. Anatomy of the dicotyledons. v.I. Oxford, Claredon Press.

Metcalfe, C.R. \& Chalk, L. 1983. Anatomy of the Dicotyledons. v.II. Oxford, University Press.

Muchow, R.C. \& Sinclair, T.R. 1989. Epidermal conductance, estomatal density and stomatal size among genotypes of Sorghum-bicolor (L.) Moench. Plant, Cell and Environment 12: $425-431$.

Napp-Zinn, K. 1984. Handbuch der Pflanzenanatomie. VIII Anatomie des Blattes, 2. Blattanatomie der Angiospermen, B. Experimentelle und ökologishe Anatomie des Angiospermenblattes. Germany, Gbdr. Borntraeger.

Paoletti, E. \& Gellini, R. 1993. Stomatal density variation in beech and holm oak leaves collected over the last 200 years. Acta Oecologia 14: 173-178.

Parkhurst, D.F. 1978. Adaptative significance of stomatal occurrence on one or both surfaces of leaves. Journal of Ecology 66: 367-383.

Ruzin, S.E. 1999. Plant microtechnique and microscopy. New York, Oxford University Press.

Ryser, U. 1992. Ultrastructure of the Epidermis of Developing Cotton (Gossypium) Seeds: Suberin, Pits, Plasmodesmata, and their Implication for Assimilate Transport into cotton Fibers. American Journal of Botany 79: 14-22.

Santos, M. \& Oliveira, P.L. 1988. Aspectos anatômicos de Ocotea porosa (Nees et Mart. ex Nees) J. Angely (Lauraceae). Insula 18: $3-22$.

Santos, M. \& Oliveira, P.L. 1995. Aspectos anatômicos de quatro espécies do gênero Ocote AUBL. (Lauraceae) ocorrentes no Rio Grande do Sul. Insula 24: 3-14.

Sokal, R.R. \& Rohlf, F.J. 1969. Biometry. San Francisco, Freeman and Company.

Solereder, H. 1908. Systematic anatomy of the dicotyledons. Oxford, Clarendon Press.

Statgraphics Statistical Graphics System. 1993. USA, Ed. Statistical Graphics Version 7.

Syvertsen, J.P.; Lloyd, J.; Mc Conchie, C.; Kriedemann, P.E. \& Farquhar, G.D. 1995. On the relationship between leaf anatomy and $\mathrm{CO}_{2}$ diffusion through the mesophyll of hypostomatous leaves. Plant, Cell and Environment 18: 149-157.

Taiz, L. \& Zeiger, E. 2004. Fisiologia vegetal. 4 ed. Porto Alegre, Editora Artmed.

Tsukaya, H. 2002. Leaf anatomy of a rheophyte, Dendranthema yoshinaganthum (Asteraceae), and of hybrids between D. yoshinaganthum and a closely related non-rheophyte, D. indicum. Journal of Plant Research 115: 329-333.

Usukura, M.; Imaichi, R. \& Kato, M. 1994. Leaf morphology of a facultative rheophyte Farfugium japonicum var. luchuense (Compositae). Journal of Plant Research 107: 263-267.

Van Steenis, C.G.G.J. 1981. Rheophytes of the world. The Netherlands, Alphenan den Rijn, Sijthoff \& Noordholff.

Van Steenis, C.G.G.J. 1987. Rheophytes of the world: supplement. Allertonia 4: 267-330. 